\title{
SECAGEM E ARMAZENAMENTO DE SEMENTES DE SORGO COM ALTO E BAIXO TEOR DE TANINO ${ }^{1}$
}

\author{
JOÃO ALMIR OLIVEIRA² ${ }^{2}$ TANISMARE TATIANA DE ALMEIDA SILVA³, \\ ÉDILA VILELA DE RESENDE VON PINHO ${ }^{4}$, LUCIANA APARECIDA DE SOUZA ABREU ${ }^{5}$
}

\begin{abstract}
RESUMO - O teor de água em que a semente é colhida, bem como a temperatura utilizada para a secagem, é fundamental para garantir a qualidade fisiológica das sementes, principalmente as de sorgo, que podem apresentar dormência secundária, por secagem em altas temperaturas. Com a realização deste trabalho, objetivou-se avaliar a qualidade fisiológica das sementes de sorgo, com alto e baixo teor de tanino e armazenadas após secagem, utilizando diferentes temperaturas. Foram utilizadas sementes das cultivares BR 305(2,28 g tanino/100 g) e BR 310 (0,52 g tanino/100 g), colhidas com teor de água $18-20 \%$, secas à sombra e em secadores artificiais, nas temperaturas de $35^{\circ} \mathrm{C}, 45^{\circ} \mathrm{C}$ e $35^{\circ} 45^{\circ} \mathrm{C}$, até atingirem $12 \%$ de teor de água. Após a secagem, essas sementes foram armazenadas em câmara fria e seca, por 0, 3 e 6 meses. Em cada época de armazenamento, as sementes foram avaliadas pelos testes de germinação, tetrazólio, condutividade elétrica, índice de velocidade de emergência, teste de frio, microscopia eletrônica de varredura e perfis enzimáticos. Foi quantificada, ainda, a concentração de tanino. Foi observado, em sementes com alto tanino, secas à temperatura de $45^{\circ} \mathrm{C}$ e armazenadas durante 6 meses, $88,5 \%$ de germinação. Houve maior porcentagem de dormência em sementes submetidas à secagem aos $35^{\circ} \mathrm{C}$. Houve aumento na concentração de tanino, aos seis meses de armazenamento, para ambos os lotes.
\end{abstract}

Termos para indexação: Sorghum bicolor, armazenamento, umidade.

\section{DRYING AND STORAGE OF HIGH AND LOW TANNIN SORGHUM SEEDS}

\begin{abstract}
Water content in harvested seed and the drying temperature are fundamental for ensuring seed physiological quality, especially in sorghum, which may show secondary dormancy when dried at high temperatures. The objective of this study was to evaluate the physiological quality of sorghum seeds, with high and low tannin contents, stored after drying at different temperatures. Seeds of the BR 305(2.28 g tannin/100 g) and BR $310(0.52 \mathrm{~g} \operatorname{tannin} / 100 \mathrm{~g})$ cultivars were collected with a water content of $18-20 \%$ and dried in the shade and in artificial dryers at temperatures of $35^{\circ} \mathrm{C}, 45^{\circ} \mathrm{C}$ and $35 / 45{ }^{\circ} \mathrm{C}$ until water content was $12 \%$. After drying, the seeds were stored in a cold, dry chamber for 0,3 and 6 months. For each storage period the seeds were evaluated with germination, tetrazolium, electric conductivity, emergence velocity index, cold, scanning electron microscopy and enzyme profile tests. Tannin concentration was also measured. High tannin seeds showed $88.5 \%$ germination when dried at $45{ }^{\circ} \mathrm{C}$ and stored for 6 months. Dormancy increased in both batches for seeds dried at $35^{\circ} \mathrm{C}$ and with increased tannin concentration at six months storage.
\end{abstract}

Index terms: Sorghum bicolor, temperature, moisture.

${ }^{1}$ Submetido em 20/08/10. Aceito para publicação em 01/04/11.

2,4 Professores do Setor de Sementes da Universidade Federal de Lavras (UFLA), Cep 37200-000 Lavras-MG, CP 3037, jalmir@dag.ufla.br, edila@dag.ufla.br
3,5 Eng. Agr., Dra., Pós-doutoranda do Setor de Sementes -UFLA, Cep 37200-000, Lavras-MG, CP 3037, mareagro@bol.com.br; luapsouza2003@yahoo.com.br 


\section{INTRODUÇÃO}

Em sorgo, os compostos fenólicos, a exemplo do tanino, são altamente correlacionados com a germinação das sementes (Queiroz, 1979). Do ponto de vista bioquímico, uma característica importante dos taninos, presentes na testa da semente de sorgo (Magalhães e Durães, 2003), é a capacidade de se ligar às proteínas por meio de pontes de hidrogênio e interação hidrofóbica (Butler, 1989).

Conforme Liu et al. (2009), um dos entraves à utilização de sementes de sorgo é o alto conteúdo de compostos fenólicos, uma vez que as proteínas se ligam fortemente ao tanino, tornando-se inativas. Muitas proteínas, a exemplo das LEAs são de fundamental importância nas sementes ortodoxas, por possuírem importante papel na proteção das estruturas citoplasmáticas das sementes durante a desidratação (Marcos Filho, 2005).

A presença de substâncias fenólicas no tegumento pode inibir a germinação das sementes de sorgo, o que Hartmann et al. (1997) definiram como dormência química. No entanto, não se sabe, realmente, se a dormência é devido à redução desses compostos ou ao armazenamento das sementes em condições de baixas temperaturas (Queiroz, 1979). Quando as sementes são mantidas armazenadas a baixas temperaturas, mantêm-se níveis aceitáveis de controle da sua qualidade. Mesmo assim, ocorre a perda da viabilidade dessas sementes e, com o envelhecimento, as membranas se tornam fracas e as enzimas perdem a atividade catalítica. O comprometimento da estrutura celular facilita o contato da enzima polifenoloxidase com compostos fenólicos, armazenados preferencialmente nos vacúolos, tornando inevitável a oxidação de fenóis que, convertidos a quinonas, reagem com proteínas, inclusive a própria polifenoloxidase, explicando sua menor atividade (Amorim e Josephson, 1975).

Para minimizar os danos durante o armazenamento e assegurar lotes de sementes com alto padrão de qualidade, muitos são os cuidados que devem ser tomados em todas as fases de produção, principalmente as relacionadas à secagem. Em sementes de sorgo (Sorghum vulgare), a secagem a temperaturas de $46{ }^{\circ} \mathrm{C}$ a $48{ }^{\circ} \mathrm{C}$ pode induzir dormência secundária, devido a alterações físicas ocorridas no tegumento da semente, provocadas pela secagem excessiva, de modo a restringir as trocas gasosas durante a embebição (Nutile e Woodstock, 1967).

Estudar o comportamento das sementes durante o armazenamento, bem como as mudanças bioquímicas e a concentração de compostos nas sementes pode trazer informações importantes, que garantam a qualidade das mesmas. Assim, objetivou-se, com a realização desta pesquisa, avaliar a qualidade das sementes de sorgo com alto e baixo teor de tanino, em função da temperatura de secagem e dos períodos de armazenamento.

\section{MATERIAL E MÉTODOS}

As análises foram conduzidas no Laboratório Central de Sementes, de Microscopia e no Laboratório de Ciência dos Alimentos da Universidade Federal de Lavras (UFLA). A semeadura foi realizada, em dezembro de 2007, na área com predominância de solo tipo Latossolo Vermelho Escuro. As correções de fertilidade e do $\mathrm{pH}$ do solo seguiram as recomendações da $5^{\text {a }}$ aproximação (Ribeiro et al., 1999). As sementes da cultivar BR 305 (2,28 mg tanino/100 g) e BR 310 (0,52 $\mathrm{mg}$ tanino/100 g), contrastantes quanto ao teor de tanino, foram fornecidas pela empresa Biomatrix, de Paracatu, MG.

O solo foi preparado de maneira convencional, seguindo as recomendações para a cultura. Cada tratamento foi constituído de quatro parcelas compostas de seis linhas de $5 \mathrm{~m}$, totalizando $30 \mathrm{~m}^{2}$, com espaçamento de $0,5 \mathrm{~m}$ entre linhas e 12 plantas por metro linear. A área útil de cada parcela consta das 4 linhas centrais. No plantio, foram utilizados $400 \mathrm{~kg} / \mathrm{ha}$ da formulação 8-20$10 \mathrm{e}$, para a adubação de cobertura, foi utilizado o sulfato de amônio, na dosagem de $350 \mathrm{~kg} / \mathrm{ha}$, parcelados em duas aplicações, aos 30 dias após o plantio e aos 45 dias. $\mathrm{O}$ controle de invasoras, assim como o controle de pragas e doenças, foi realizado sempre que necessário. As panículas foram colhidas quando as sementes apresentavam teor de água de $18 \%-20 \%$ e a debulha realizada manualmente. Logo após a colheita, uma parte das sementes foi seca à sombra e outra parte foi seca em protótipos de secadores estacionários, regulados na temperatura constante de $35^{\circ} \mathrm{C}$ e $45{ }^{\circ} \mathrm{C}$. Em outro protótipo, a secagem foi iniciada com $35^{\circ} \mathrm{C}$, até as sementes atingirem $15 \%$ de grau de umidade e, em seguida, a temperatura foi aumentada para $45^{\circ} \mathrm{C}$, até o grau de umidade de $12 \%$. Após a secagem, as sementes foram embaladas em saco de papel multifoliado e armazenadas em câmara fria e seca. As avaliações foram realizadas aos 0,3 e 6 meses de armazenamento, por meio das determinações descritas a seguir.

Determinação do grau de umidade: foi realizada pelo método da estufa, aos $105{ }^{\circ} \mathrm{C}$, durante 24 horas, conforme as Regras para Análise de Sementes (Brasil, 2009); teste de germinação: o substrato foi o papel do 
tipo "Germitest", umedecido com água destilada $(2,5 \mathrm{X}$ o peso seco do papel). As sementes foram colocadas em germinador a $25^{\circ} \mathrm{C}$ e a avaliação realizada aos 4 e 10 dias após a semeadura. Foram consideradas como plântulas normais aquelas que possuíam, no mínimo, duas raízes seminais e raiz principal maior que $5 \mathrm{~cm}$. As sementes remanescentes de cada tratamento foram submetidas ao teste de tetrazólio. Após o corte, a metade de cada semente foi colocada em recipiente de plástico escuro, imersa em solução de sal de tetrazólio em $0,5 \%$, por 2 horas aos $30{ }^{\circ} \mathrm{C}$. Após a coloração, as partes da semente foram avaliadas para a determinação da viabilidade; emergência de plântulas: a semeadura foi realizada em bandeja plástica contendo, como substrato, a mistura de areia e terra, na proporção de $2: 1$, umedecido até $70 \%$ da capacidade de retenção. Após a semeadura, as bandejas foram mantidas em câmara de crescimento vegetal, a $25^{\circ} \mathrm{C}$, em regime alternado de luz e escuro (12 horas). As plântulas foram avaliadas diariamente, após o primeiro dia de emergência e calculado o índice de velocidade de emergência segundo fórmula proposta por Maguire (1962). Aos 10 dias após a semeadura, computou-se o número de plântulas normais; teste de frio: a semeadura foi realizada em bandeja plástica contendo, como substrato, a mistura de areia e terra, na proporção de 2:1, umedecido até $70 \%$ da capacidade de retenção. Após a semeadura, as bandejas foram inicialmente mantidas em câmara fria e seca, aos $10{ }^{\circ} \mathrm{C} / 50 \%$ de UR, por 7 dias. Após esse período, foram transferidas para câmara de crescimento, a $25{ }^{\circ} \mathrm{C}$ por sete dias, quando foi realizada a contagem das plântulas; teste de condutividade elétrica de massa: as sementes foram contadas, pesadas e colocadas em copos plásticos contendo $75 \mathrm{~mL}$ de água deionizada. Após 24 horas de embebição a $25{ }^{\circ} \mathrm{C}$, foi realizada a leitura com auxílio de um condutivímetro de massa e os resultados expressos em $\mu \mathrm{S} / \mathrm{cm} / \mathrm{g}$ Krzyzanowski et al. (1999); análises eletroforéticas: em cada época de avaliação foram retiradas duas amostras de 100 sementes e armazenadas à temperatura de $-86^{\circ} \mathrm{C}$ em deep freezer. Para a extração da enzima esterase, foi utilizado o tampão Tris $\mathrm{HCl} 0,2 \mathrm{M} \mathrm{pH} 8,0+(0,1 \%$ de $\beta$ mercaptoetanol $)$, na proporção de $250 \mu \mathrm{L}$ por $100 \mathrm{mg}$ de amostra. O material foi homogeneizado, mantido overnight, em geladeira, seguido de centrifugação, a $16.000 \mathrm{xg}$, por 30 minutos, a $4{ }^{\circ} \mathrm{C}$. A corrida eletroforética foi realizada em sistema de géis de poliacrilamida, aos 7,5\% (gel separador) e 4,5\% (gel concentrador). O sistema gel/eletrodo utilizado foi o Trisglicina $\mathrm{pH} 8,9$. Foram aplicados $50 \mu \mathrm{L}$ do sobrenadante da amostra e a corrida efetuada, a 120 V, por 6 horas. Para análise eletroforética de proteínas resistentes ao calor (tipo LEA) e a determinação da atividade da polifenoloxidase, as sementes foram embebidas em papel tipo germitest, a $25^{\circ} \mathrm{C}$, por período de 5 horas. Posteriormente as sementes foram maceradas na presença de solução tampão (50 mM tris- $\mathrm{HCl}$ 7,5; $500 \mathrm{mM} \mathrm{NaCl} ; 5 \mathrm{mM} \mathrm{MgCl}$; 1 mM PMSF), na proporção de 1:10 (peso material: volume tampão de extração) e transferidos para microtubos. O material foi homogeneizado em vortex e centrifugado, a $16.000 \mathrm{xg}$, por 30 minutos, aos $4{ }^{\circ} \mathrm{C}$. O sobrenadante foi deixado em banho-maria, a $85{ }^{\circ} \mathrm{C}$, por 15 minutos e novamente centrifugado. Posteriormente, $70 \mu \mathrm{L}$ do sobrenadante foram misturados a $40 \mu \mathrm{L}$ de solução tampão da amostra (2,5 mL de glicerol; 0,46 g de SDS; $20 \mathrm{mg}$ de azul de Bromofenol) e deixados em banho-maria com água em ebulição por cinco minutos. Foram aplicados $50 \mu \mathrm{L}$ no gel de poliacrilamida SDS-PAGE em 12,5\% (gel separador) e $6 \%$ (gel concentrador). A corrida eletroforética foi realizada a $120 \mathrm{~V}$ por 6 horas, o gel corado em Coomassie Blue a $0,05 \%$ durante 12 horas e descorado em solução de ácido acético 10\% (Alfenas et al., 1991). A Determinação da atividade da enzima polifenoloxidase, foi realizada de acordo com o método descrito por Draetta e Lima (1976), em que as amostras foram previamente moídas, em moinho refrigerado a $4{ }^{\circ} \mathrm{C}$, adicionando-se nitrogênio líquido. A cada $5 \mathrm{~g}$ de amostra de sementes foram adicionados $40 \mathrm{~mL}$ da solução tampão de fosfato de potássio $0,1 \mathrm{M}$ pH 6,0 e homogeneizado em vortex, por 5 minutos. Em seguida, as amostras foram filtradas em papel de filtro Whatman $n^{\circ} 1$, à vácuo. Na determinação dessa enzima, foi utilizado extrato da amostra sem o DOPA (L-3,4dihydroxyphenyalanina) como branco. Foi realizada a curva padrão. A leitura da enzima polifenoloxidase foi realizada em espectrofotômetro Schumaz e os resultados expressos em U/min/g; quantificação de tanino, as sementes foram trituradas e $5 \mathrm{~g}$ foram colocados em tubos de ensaio, acrescentando-se $30 \mathrm{ml}$ de metanol 80\%. Essa mistura foi fervida por um período de 20 minutos em refluxo na chapa elétrica para tubo aos $150{ }^{\circ} \mathrm{C}$. A quantificação foi realizada pelo método químico-colorimétrico de FolinDennis e as leituras realizadas em espectrofotômetro, a $760 \mathrm{~nm}$; microscopia eletrônica, as sementes de cada tratamento foram imersas em solução fixativa (Karnovisk's modificada), pH 7,2, por 24 horas. Em seguida, foram lavadas em tampão cacodilato, por três vezes. A pósfixação foi feita em tetróxido de ósmio $1 \%$, por uma hora. Após esse período, foram realizadas lavagens com água 
destilada por três vezes e desidratação em gradiente de acetona aos $25 \%, 50 \%, 75 \%, 90 \%$ e $100 \%$, durante 10 minutos. As amostras foram levadas para o aparelho de ponto crítico, onde eliminou todo o resíduo de acetona para posterior montagem em stubs para revestimento com ouro. Em cada stub foram colocadas seis repetições de cada amostra. A visualização das amostras foi feita em microscópio eletrônico de varredura LEO Evo 40.

$\mathrm{O}$ delineamento experimental e a análise estatística foram realizados em esquema fatorial $(2 \times 4 \times 3)$, sendo dois lotes BR 305 (2,28 mg tanino/100 g) e BR 310 $(0,52 \mathrm{mg}$ tanino/100 g), 4 temperaturas de secagem (à sombra e aos $35{ }^{\circ} \mathrm{C}, 45^{\circ} \mathrm{C}$ e $35^{\circ}-45^{\circ} \mathrm{C}$ ) e três épocas de armazenamento em câmara fria e seca (0,3 e 6 meses). O teste de média utilizado foi o Scott-Knott aos 5\% e análises de regressão foram realizadas para as variáveis quantitativas e transformação dos dados $V_{x}+0,5$, para a variável dormência. Nas análises, foram utilizadas 4 repetições de 50 sementes em cada teste, com exceção da análise enzimática da polifenoloxidade, para a qual utilizaram-se 2 repetições.

\section{RESULTADOS E DISCUSSÃO}

Na Tabela 1 estão apresentados os dados relativos aos valores de germinação e de condutividade elétrica, sendo possível notar a interação tripla entre os fatores avaliados. Não foram verificadas diferenças significativas entre os valores de germinação obtidos em sementes do lote BR 305 submetidas às diferentes temperaturas de secagem. Durante o período de armazenamento, a maior porcentagem de germinação ocorreu aos seis meses, para as sementes da cultivar BR 305 secas aos $45{ }^{\circ} \mathrm{C}$. Nas demais temperaturas de secagem, não houve diferenças significativas. Em relação ao lote BR 310, houve aumento na porcentagem de germinação a partir dos 3 meses de armazenamento para as sementes submetidas à secagem natural, a $45{ }^{\circ} \mathrm{C}$ e a $35^{\circ} / 45^{\circ} \mathrm{C}$. Para as sementes secas naturalmente, houve redução no valor de germinação aos seis meses de armazenamento.

TABELA 1. Resultados médios (\%) de plântulas normais avaliadas pelo teste de germinação e valores de condutividade elétrica $\left(\mu \mathrm{S} . \mathrm{cm}^{-1} \cdot \mathrm{g}^{-1}\right)$, em sementes de sorgo após secagem em diferentes temperaturas e armazenadas em câmara fria e seca.

\begin{tabular}{|c|c|c|c|c|c|c|c|c|c|}
\hline \multirow{3}{*}{ Época } & \multirow{3}{*}{ Meses } & \multicolumn{4}{|c|}{ Lote BR 305} & \multicolumn{4}{|c|}{ Lote BR 310} \\
\hline & & \multicolumn{8}{|c|}{ Temperatura de secagem $\left({ }^{\circ} \mathrm{C}\right)$} \\
\hline & & Natural & 35 & 45 & $35 / 45$ & Natural & 35 & 45 & $35 / 45$ \\
\hline \multirow{3}{*}{ Germinação } & 0 & $76 \mathrm{Aa}$ & $74 \mathrm{Aa}$ & $73 \mathrm{Ba}$ & $80 \mathrm{Aa}$ & $74 \mathrm{Ba}$ & $76 \mathrm{Aa}$ & $74 \mathrm{Ba}$ & $70 \mathrm{Ba}$ \\
\hline & 3 & $85 \mathrm{Aa}$ & $81 \mathrm{Aa}$ & $80 \mathrm{Ba}$ & $86 \mathrm{Aa}$ & 83 Aa & $76 \mathrm{Ab}$ & $87 \mathrm{Aa}$ & $92 \mathrm{Aa}$ \\
\hline & 6 & $81 \mathrm{Aa}$ & $82 \mathrm{Aa}$ & 89 Aa & $81 \mathrm{Aa}$ & $72 \mathrm{Bb}$ & $75 \mathrm{Ab}$ & $83 \mathrm{Aa}$ & $86 \mathrm{Aa}$ \\
\hline \multirow{3}{*}{$\begin{array}{l}\text { Condutividade } \\
\text { elétrica }\end{array}$} & 0 & $0,4 \mathrm{Bb}$ & $0,2 \mathrm{Aa}$ & $0,3 \mathrm{Aa}$ & $0,2 \mathrm{Aa}$ & $0,2 \mathrm{Aa}$ & $0,2 \mathrm{Aa}$ & $0,4 \mathrm{Ab}$ & $0,2 \mathrm{Aa}$ \\
\hline & 3 & $0,4 \mathrm{Ba}$ & $0,3 \mathrm{Aa}$ & $0,4 \mathrm{Bb}$ & $0,4 \mathrm{Bb}$ & $0,4 \mathrm{Bb}$ & $0,3 \mathrm{Aa}$ & $0,6 \mathrm{Bc}$ & $0,5 \mathrm{Cc}$ \\
\hline & 6 & $0,3 \mathrm{Aa}$ & $0,3 \mathrm{Aa}$ & $0,3 \mathrm{Aa}$ & $0,4 \mathrm{Bb}$ & $0,4 \mathrm{Ba}$ & $0,5 \mathrm{Ba}$ & $0,4 \mathrm{Aa}$ & $0,4 \mathrm{Ba}$ \\
\hline
\end{tabular}

Médias seguidas pela mesma letra maiúscula na coluna e minúscula na linha, para cada lote, não diferem entre si, pelo teste de Scott-Knott, aos $5 \%$ de probabilidade.

Pelos resultados de condutividade elétrica (Tabela 1), antes do armazenamento, a secagem natural das sementes da cultivar BR 305 foi mais prejudicial às membranas celulares, enquanto para o lote BR 310, na mesma época, a temperatura de $45{ }^{\circ} \mathrm{C}$ propiciou um aumento da condutividade elétrica. Notam-se, nas sementes armazenadas após secagem sob alta temperatura, maiores valores de condutividade elétrica. Aos seis meses, para sementes do lote BR 305, secas naturalmente, observa-se redução nesses valores. Chen e Burris (1991) observaram que sementes de milho, quando pré-condicionadas à baixa temperatura, mantiveram preservados seus sistemas de membranas.

Há relatos de que a deterioração da semente à temperatura de $10{ }^{\circ} \mathrm{C}$ parece não estar diretamente relacionada à perda da integridade das membranas, sugerindo tal fato ao seu reparo ou reorganização durante o armazenamento a baixas temperaturas (Fessel et al., 2006; 
Panobianco et al., 2007). O aumento da porcentagem de germinação após armazenamento (Tabela 1), observado nas sementes secas sob temperaturas de $45^{\circ} \mathrm{C}$ e $35^{\circ} / 45$ ${ }^{\circ} \mathrm{C}$, pode ser explicado pela possível quebra de dormência proporcionada pela exposição das sementes a baixas temperaturas $\left(10^{\circ} \mathrm{C}\right)$, durante o armazenamento.

Para a variável dormência, foi verificada interação dupla entre os fatores lote e época de armazenamento, lote e temperatura de secagem, época de armazenamento e temperatura de secagem. Na Tabela 2 observa-se a porcentagem de sementes dormentes avaliadas pelo teste de tetrazólio. De maneira geral, observa-se redução da dormência das sementes ao longo do armazenamento, para todas as temperaturas testadas. Para Chen e Burris (1991), altas temperaturas de secagem reduzem a germinação e o vigor das sementes, podendo alterar suas características físicas e químicas. A suscetibilidade das sementes aos danos por secagem é função das condições de secagem, do conteúdo de água e da qualidade inicial das sementes aliada aos aspectos genéticos.

TABELA 2. Resultados médios (\%) de sementes dormentes avaliadas pelo teste de tetrazólio em sementes de sorgo após secagem e armazenadas em câmara fria e seca.

\begin{tabular}{ccccc}
\hline \multirow{2}{*}{ Época de armazenamento (meses) } & \multicolumn{4}{c}{ Temperatura de secagem $\left({ }^{\circ} \mathrm{C}\right)$} \\
\cline { 2 - 4 } & Natural & 35 & 45 & $35 / 45$ \\
\hline 0 & $1,3 \mathrm{Ab}$ & $5,0 \mathrm{Aa}$ & $3,0 \mathrm{Aa}$ & $1,5 \mathrm{Ab}$ \\
3 & $0,8 \mathrm{Aa}$ & $1,5 \mathrm{Ba}$ & $1,0 \mathrm{Ba}$ & $0,8 \mathrm{Aa}$ \\
6 & $0,0 \mathrm{Aa}$ & $1,3 \mathrm{Ba}$ & $0,0 \mathrm{Ba}$ & $0,8 \mathrm{Aa}$ \\
\hline \multirow{2}{*}{ Época de armazenamento (meses) } & \multicolumn{3}{c}{$\mathrm{Lote}$} \\
\hline 0 & $\mathrm{Br} \mathrm{305}$ & $0,3 \mathrm{Ab}$ \\
3 & $5,1 \mathrm{Aa}$ & $0,4 \mathrm{Ab}$ \\
6 & $1,6 \mathrm{Ba}$ & $0,0 \mathrm{Ab}$ \\
\hline
\end{tabular}

Médias seguidas pela mesma letra maiúscula na coluna e minúscula na linha, não diferem entre si, pelo teste de Scott-Knott, aos 5\% de probabilidade.

Com relação às cultivares, houve redução na porcentagem de sementes dormentes ao longo do armazenamento para a cultivar BR 305 , independente da temperatura de secagem e a porcentagem de sementes dormentes foi maior na cultivar BR 305, em todas as épocas de armazenamento. Queiroz (1979) observou que o teor de tanino foi altamente correlacionado com a germinação das sementes e que, de modo geral, a dormência não perdura por mais de três meses. As sementes de sorgo tendem a perder a dormência com o armazenamento. Não se sabe, portanto, se é devido a uma estratificação a baixas temperaturas ou à redução de compostos fenólicos no tegumento.

Independente da época de armazenamento (Tabela 3) verifica-se que a porcentagem de sementes dormentes foi maior quando secas sob temperatura de secagem de $35^{\circ} \mathrm{C}$, para o lote com maior teor de tanino (BR 305). Não foram identificadas diferenças entre os tratamentos de secagem natural, $45^{\circ} \mathrm{C}$ e alternada. Para o lote com menor teor de tanino (BR 310), não houve diferença entre os tratamentos de secagem. Pelos resultados, observou-se que a temperatura de secagem de $35^{\circ} \mathrm{C}$ favoreceu maiores valores de sementes dormentes. A temperatura de secagem $\left(45^{\circ} \mathrm{C}\right)$ não influenciou a porcentagem de sementes dormentes.

TABELA 3. Resultados médios (\%) de sementes dormentes avaliadas pelo teste de tetrazolio em sementes de sorgo, cultivar BR 305 e BR 310 após secagem e armazenadas em câmara fria e seca.

\begin{tabular}{ccc}
\hline Temperatura de & \multicolumn{3}{c}{ Lote } \\
\cline { 2 - 3 } secagem $\left({ }^{\circ} \mathrm{C}\right)$ & $\mathrm{Br} 305$ & $\mathrm{Br} 310$ \\
\hline Natural & $1,0 \mathrm{Ba}$ & $0,3 \mathrm{Aa}$ \\
35 & $5,0 \mathrm{Aa}$ & $0,2 \mathrm{Ab}$ \\
45 & $2,7 \mathrm{Ba}$ & $0,0 \mathrm{Ab}$ \\
$35 / 45$ & $1,7 \mathrm{Ba}$ & $0,3 \mathrm{Ab}$ \\
\hline
\end{tabular}

Médias seguidas pela mesma letra maiúscula na coluna e minúscula na linha, não diferem entre si, pelo teste de Scott-Knott, aos 5\% de probabilidade. 
Na Tabela 4 está descrita a concentração de tanino determinado nas sementes de sorgo. Pela análise de variância dos dados, observa-se interação tripla para os fatores estudados. O teor de tanino aumentou com o armazenamento e esse aumento pode ser devido à polimerização de monômeros de flavan-3-ol, que formam essas moléculas. Essa polimerização é favorecida pela secagem das sementes (Butler, 1989). Iaderoza et al. (1989) verificaram redução no conteúdo de tanino condensado durante o armazenamento das cultivares de feijão.

TABELA 4. Resultados médios (mg/100 g) de tanino em sementes de sorgo após secagem e armazenadas em câmara fria e seca.

\begin{tabular}{|c|c|c|c|c|c|c|c|c|}
\hline \multirow{2}{*}{\multicolumn{2}{|c|}{$\begin{array}{l}\text { Armaz. } \\
\text { (meses) }\end{array}$}} & \multicolumn{3}{|c|}{ Lote BR 305} & & \multicolumn{2}{|c|}{ Lote BR 310} & \multirow[b]{3}{*}{$35 / 45$} \\
\hline & & \multicolumn{6}{|c|}{ Temperatura de secagem $\left({ }^{\circ} \mathrm{C}\right)$} & \\
\hline & ural & 35 & 45 & $35 / 45$ & Natural & 35 & 45 & \\
\hline 0 & $1628 \mathrm{Ba}$ & 1644Ba & $1425 \mathrm{Cc}$ & $1555 \mathrm{Cb}$ & $477 \mathrm{Ba}$ & $361 \mathrm{Bb}$ & $356 \mathrm{Bb}$ & $495 \mathrm{Ba}$ \\
\hline 3 & $1501 \mathrm{Cc}$ & $1376 \mathrm{Cd}$ & $1651 \mathrm{Bb}$ & $1785 \mathrm{Ba}$ & $295 \mathrm{Ca}$ & $321 \mathrm{Ba}$ & $261 \mathrm{Ca}$ & $313 \mathrm{Ca}$ \\
\hline 6 & $2307 \mathrm{Aa}$ & $2206 \mathrm{Ab}$ & $2195 \mathrm{Ab}$ & $2236 \mathrm{Ab}$ & 781Aa & 818Aa & 803Aa & 783Aa \\
\hline
\end{tabular}

Médias seguidas pela mesma letra maiúscula na coluna e minúscula na linha, para cada lote, não diferem entre si, pelo teste de Scott-Knott, aos $5 \%$ de probabilidade.

O aumento na concentração de tanino não apresentou a mesma tendência da porcentagem de sementes dormentes, embora seja sugerida uma relação entre este componente e dormência nas sementes. Essa divergência pode ser devido ao método utilizado para a quantificação do tanino, uma vez que essa metodologia não diferencia taninos condensados de outros compostos fenólicos (Magalhães e Durães, 2003). No entanto, esses autores ressaltam que o sorgo não tem mostrado, na sua constituição química, grande quantidades de outros compostos fenólicos além do tanino.

Almeida (1988) sugere a cumarina como um possível inibidor de germinação, a qual tem a capacidade de induzir a dormência de sementes sensíveis à luz, principalmente pela inibição da ação de giberelina verificada em plantas de ervilha.
De acordo com a análise de variância, não houve efeito significativo da interação entre os fatores investigados para as variáveis teste de frio e emergência. Considerando-se os efeitos isolados, foram observados efeitos significativos de temperatura de secagem para teste de frio e índice de velocidade de emergência e de época de armazenamento para teste de frio, índice de velocidade de emergência e porcentagem de emergência.

Em relação aos métodos de secagem a que as sementes foram submetidas, verificou-se que não houve diferenças significativas entre as médias de germinação após teste de frio (Tabela 5), para as temperaturas de $35{ }^{\circ} \mathrm{C}, 45{ }^{\circ} \mathrm{C}$ e $35^{\circ} / 45^{\circ} \mathrm{C}$, tendo a secagem natural à sombra proporcionado o pior desempenho das sementes de sorgo. Já para o índice de velocidade de emergência, a menor média foi verificada para o tratamento de secagem aos $35^{\circ} \mathrm{C}$.

TABELA 5. Resultados médios de vigor avaliadas pelo teste de frio e índice de velocidade de emergência (IVE) após secagem.

\begin{tabular}{ccc}
\hline Temperatura de secagem $\left({ }^{\circ} \mathrm{C}\right)$ & Teste de frio $(\%)$ & IVE \\
\hline Natural & $67 \mathrm{~B}$ & $28,9 \mathrm{~A}$ \\
35 & $72 \mathrm{~A}$ & $24,2 \mathrm{~B}$ \\
45 & $74 \mathrm{~A}$ & $26,7 \mathrm{~A}$ \\
$35 / 45$ & $73 \mathrm{~A}$ & $27,7 \mathrm{~A}$ \\
\hline
\end{tabular}

Médias seguidas pela mesma letra maiúscula na coluna para cada teste, não diferem entre si, pelo teste de Scott-Knott, aos 5\% de probabilidade. 
Durante o período de armazenamento (Tabela 6), podese observar o maior vigor das sementes aos seis meses, tanto pelo teste de frio como pelo índice de velocidade de emergência. Esse resultado não concorda com o observado por Marcos Filho et al. (1987) e Silva et al. (2001) de que houve redução nos valores, com o decorrer do armazenamento. Segundo Burris e Navratil (1980), o dano por secagem pode aumentar a suscetibilidade a injúria ao frio em sementes de milho. $\mathrm{O}$ aumento nos valores de germinação aos seis meses, avaliado pelo teste de frio, pode ser em decorrência da redução da porcentagem de sementes dormentes, que ocorreu para ambos os lotes. O mesmo comportamento é verificado pelo índice de velocidade de emergência.

TABELA 6. Resultados médios de vigor avaliadas pelo teste de emergência, teste de frio e índice de velocidade de emergência (IVE), durante armazenamento em câmara fria e seca.

\begin{tabular}{cccc}
\hline Época de & \multicolumn{3}{c}{ Avaliações } \\
\cline { 2 - 4 } armazenamento (meses) & Teste de frio (\%) & IVE & Emergência (\%) \\
\hline 0 & $71 \mathrm{~B}$ & $19,7 \mathrm{C}$ & $75,0 \mathrm{~B}$ \\
3 & $69 \mathrm{~B}$ & $29,4 \mathrm{~B}$ & $83,5 \mathrm{~A}$ \\
6 & $75 \mathrm{~A}$ & $31,6 \mathrm{~A}$ & $80,0 \mathrm{~A}$ \\
\hline
\end{tabular}

Médias seguidas pela mesma letra maiúscula na coluna para cada teste, não diferem entre si, pelo teste de Scott-Knott, aos 5\% de probabilidade.

Esse fato pode ser confirmado pelos padrões eletroforéticos da enzima esterase (Figura 1A), os quais reforçam os resultados obtidos no teste de condutividade elétrica. Para a cultivar BR 305, observou-se menor atividade da enzima esterase. No entanto, à temperatura de $45^{\circ} \mathrm{C}$, aos três meses de armazenamento, não foi verificada, nas sementes, nenhuma atividade dessa enzima. Isso pode ser atribuído à degradação das membranas celulares, o que pode ser verificado pelos resultados de condutividade elétrica (Tabela 1). Conforme Lin (1990), a redução do vigor de sementes envelhecidas poderia ser causada pela perda do controle sobre a compartimentalização intracelular e alterações nas concentrações de metabólitos, resultado da perda de lipídios da membrana.

As alterações nos padrões desta enzima (Figura 1A) evidenciam a ocorrência de eventos deteriorativos. A esterase é uma enzima envolvida em reações de hidrólise de ésteres, estando diretamente ligada ao metabolismo dos lipídios, como os fosfolipídios totais de membrana (Santos et al., 2005). De maneira geral, houve menor intensidade de bandas na cultivar BR 305 com alto conteúdo de tanino, para a proteína resistente ao calor (Figura 1B). Conforme Liu et al. (2009), um dos entraves à utilização do sorgo é o alto conteúdo de compostos fenólicos nas sementes, uma vez que as proteínas se ligam fortemente ao tanino e essa interação pode influenciar na análise eletroforética. A interação tanino proteína pode ter sido responsável pela ausência de bandas nas variedades com alto conteúdo de tanino.

Por outro lado, as proteínas resistentes ao calor são ricas em glicina e outros aminoácidos hidrofílicos e apresentam poucos resíduos hidrofóbicos. Para Magalhães et al. (1997), as principais características das proteínas que influenciam na complexação com tanino são alto peso molecular, estrutura mais aberta e flexível, ponto isoelétrico e conteúdo de prolina, sendo esta última a mais importante, uma vez que a prolina tem característica hidrofóbica.

Para as sementes com baixo tanino, não foram detectadas diferenças nos padrões de banda durante o armazenamento e entre as temperaturas de secagem. No entanto, para as sementes com alto teor de tanino, aos três meses, foi observada ausência de bandas em sementes submetidas às temperaturas de $45^{\circ} \mathrm{C}, 35^{\circ} / 45^{\circ} \mathrm{C}$ e secagem natural. Já aos seis meses, essa ausência foi observada em sementes secas aos $35^{\circ} \mathrm{C}$ e ao natural.

Em relação às sementes da cultivar BR 310, não foram observadas diferenças entre os padrões eletroforéticos da esterase e proteína resistente ao calor. Estudos têm demonstrado que percentuais abaixo de $0,70 \%$, na semente de sorgo, são devido a outros fenóis e não ao tanino condensado (Ávila, 2007), sendo, portanto, essa cultivar considerada com ausência de tanino (Magalhães et al., 1997). E, sem a presença de tanino, pode não ter ocorrido complexação suficiente para inativar essas proteínas mantendo a sua atividade. 
A)

Sem armazenamento

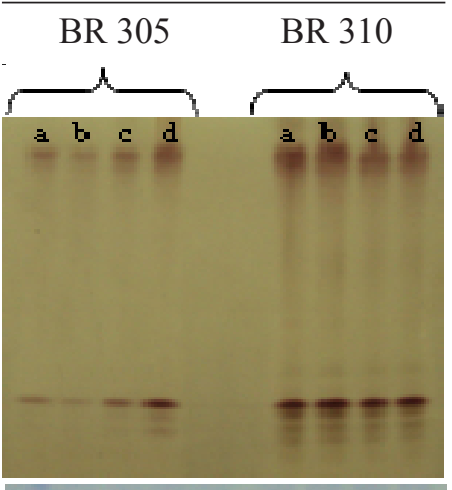

$a b c d a b=d$

B)
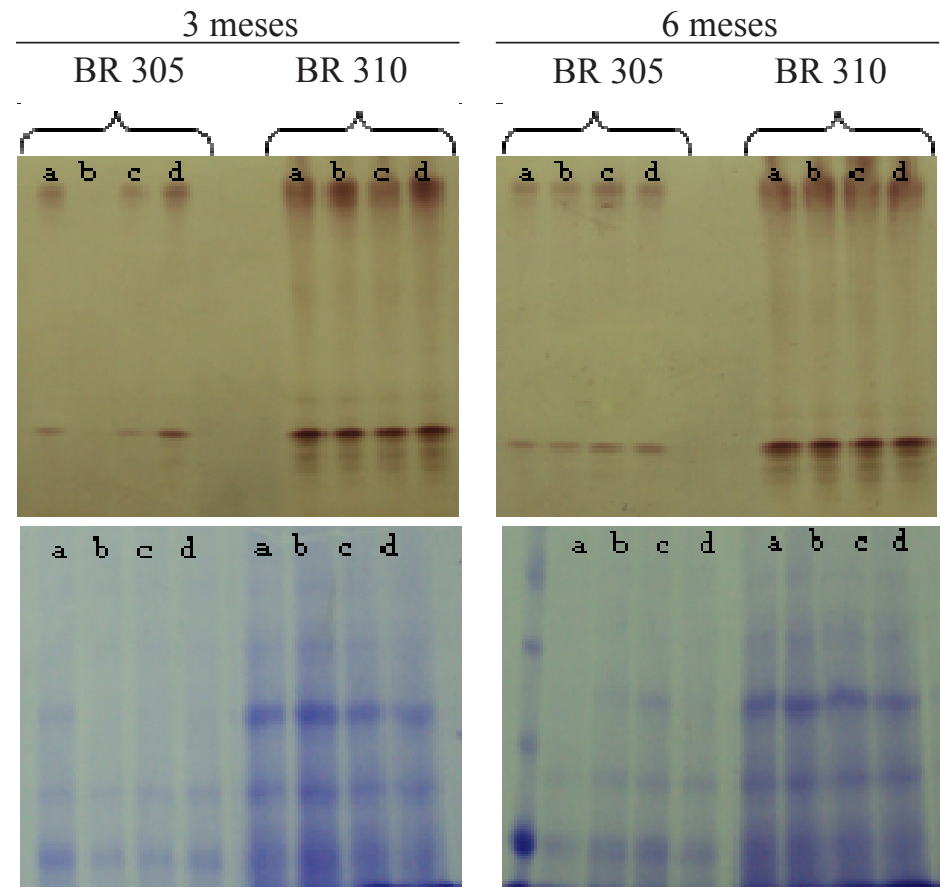

FIGURA 1. Perfil enzimático da esterase (A) e padrão eletroforético da proteína resistente ao calor (B) de sementes de sorgo submetidas à secagem aos $35^{\circ} \mathrm{C}(\mathrm{a}), 45^{\circ} \mathrm{C}(\mathrm{b}), 35^{\circ} / 45^{\circ} \mathrm{C}$ (c) e natural (d).

A atividade da enzima polifenoloxidase está representada na Figura 2. Para o lote BR 310, não houve variação na atividade da enzima polifenoloxidase com o armazenamento, exceto para a secagem natural antes do armazenamento. Já para a BR 305 com alto teor de tanino, a maior atividade foi verificada na secagem natural para as sementes sem armazenamento e naquelas secas com $35^{\circ} \mathrm{C}$ e $35^{\circ} / 45^{\circ} \mathrm{C}$, aos seis meses de armazenamento.
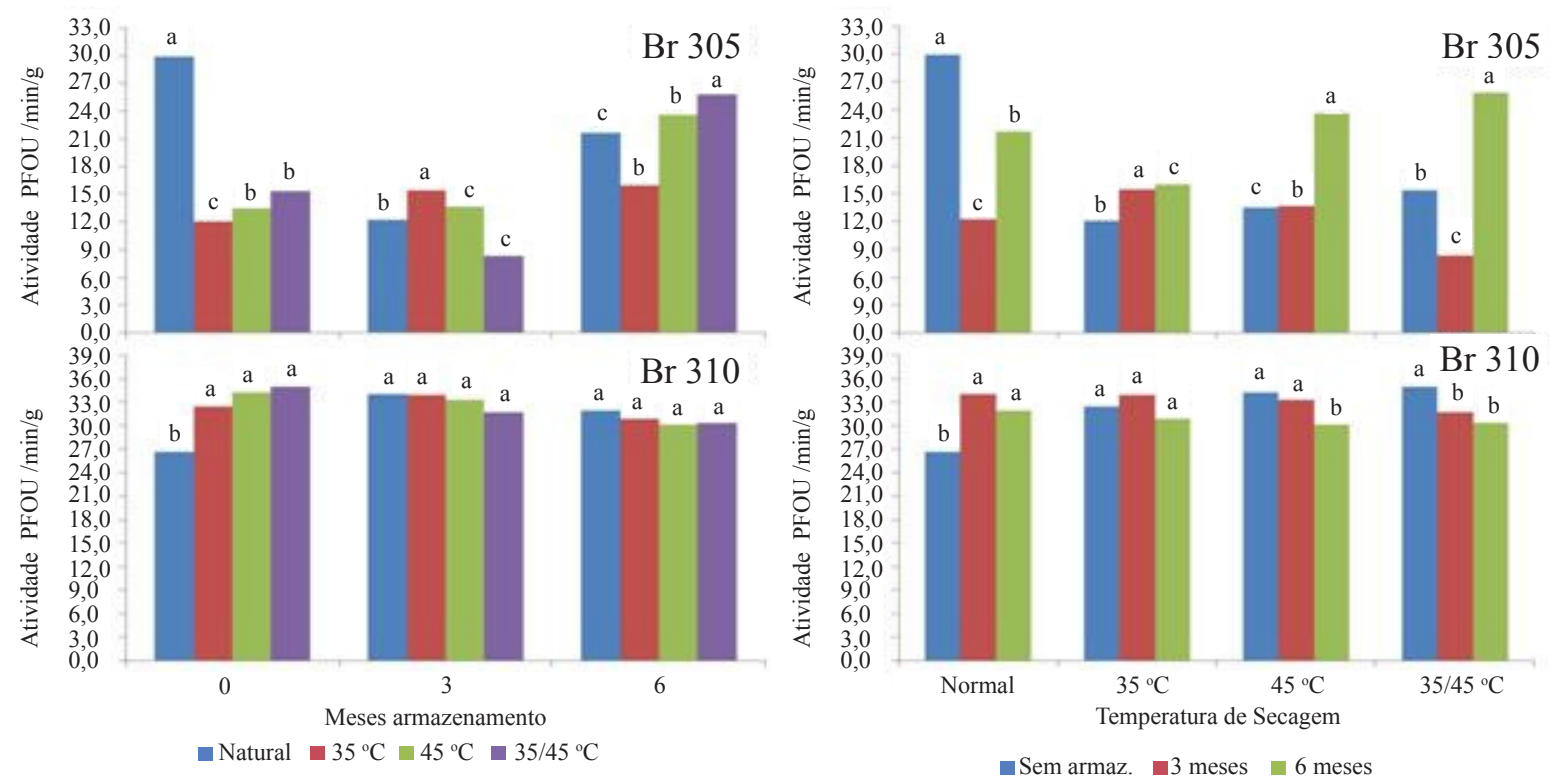

FIGURA 2. Atividade da enzima polifenoloxidase (U/min/g) em sementes de sorgo dos lotes das cultivares BR 305 e BR 310 submetidas à secagem sob $35^{\circ} \mathrm{C}, 45^{\circ} \mathrm{C}, 35 / 45^{\circ} \mathrm{C}$ e natural, e armazenadas em câmara fria e seca. 
A semente ou cariopse de sorgo é constituída por três componentes: pericarpo, endosperma e embrião. $\mathrm{O}$ pericarpo origina-se da parede do ovário e está dividido em três tecidos histológicos: epicarpo, mesocarpo e endocarpo. Em sorgo, ao contrário de outras gramíneas, o mesocarpo contém grânulos de amido (Waniska, 2000). Durante o processo de secagem podem ocorrer danos, sendo a redução do volume celular o mais importante dano em tecidos hidratados (Pammenter e Berjak, 1999), uma vez que o transporte de solutos nas células vegetais se dá por

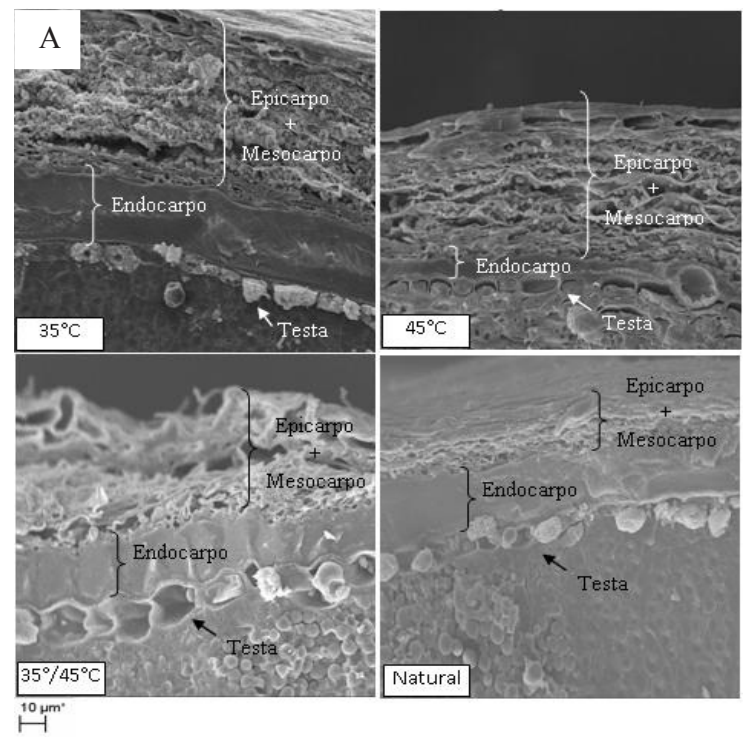

meio de interconexões por plasmodesmas (Taiz e Zeigner, 2004). Essas alterações podem causar prejuízos no vigor e na germinação das sementes. No entanto, na Figura 3A observam-se modificações na estrutura das células da testa e do endocarpo de sementes da cultivar BR 305. Na secagem aos $35^{\circ} / 45^{\circ} \mathrm{C}$, ocorreram deformações nas células da testa em relação à secagem natural e sob temperatura de $45{ }^{\circ} \mathrm{C}$, sendo observada maior espessura do endocarpo na secagem natural, com menores prejuízos à germinação, no início do armazenamento.

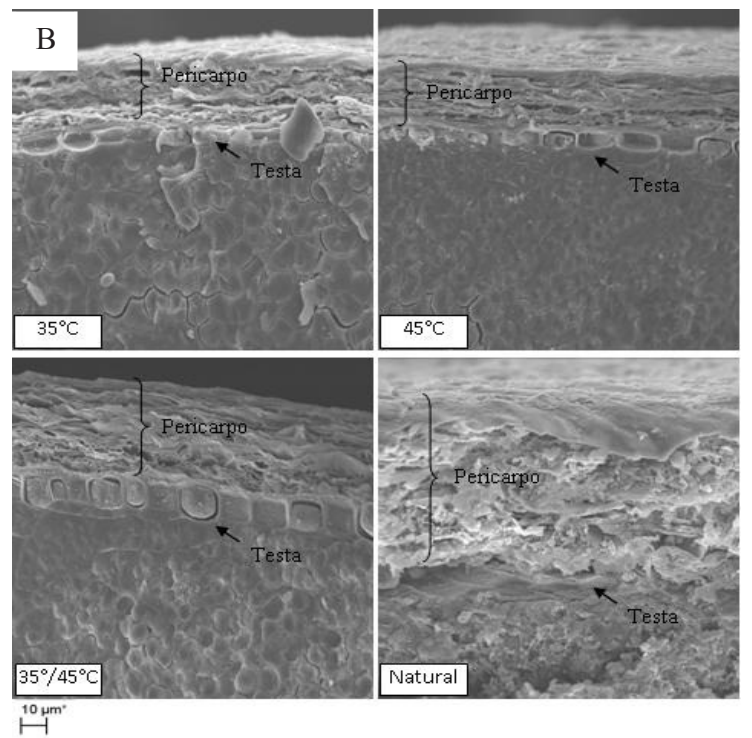

FIGURA 3. Imagens obtidas por meio de microscópio eletrônico de varredura (1000X) de sementes de sorgo cultivar BR 305(A) e BR 310 (B) submetidas à secagem, antes do armazenamento.

Já com relação às sementes da cultivar BR 310 , observa-se, na Figura $3 \mathrm{~B}$, que a testa das sementes secas sob temperatura de $35^{\circ} / 45{ }^{\circ} \mathrm{C}$ está mais espessa, quando comparadas àquelas secas a temperaturas de $35^{\circ} \mathrm{C}$ ou de $45{ }^{\circ} \mathrm{C}$. Verifica-se que a menor espessura ocorreu na temperatura de $35^{\circ} \mathrm{C}$ do que de $45^{\circ} \mathrm{C}$. Comparando-se com os valores de condutividade elétrica, a maior lixiviação foi verificada quando as sementes foram submetidas à secagem de $45^{\circ} \mathrm{C}$.

Pelas imagens da Figura 4A, referentes às sementes da cultivar BR 305 com 3 meses de armazenamento, observase que as células estão mais tabulares e menores em comparação àquelas secas naturalmente. Pelos resultados fisiológicos dessas sementes não foram observadas diferenças nos valores de germinação. No entanto, foram observados maiores valores de condutividade quando as sementes foram submetidas à secagem de $45^{\circ} \mathrm{C}$ e $35^{\circ} / 45$
${ }^{\circ} \mathrm{C}$ (Tabela 1). Foi também observada menor espessura da testa (Figura 4B) nas sementes do lote BR 310 submetidas à temperatura de $35{ }^{\circ} \mathrm{C}$ e de $35^{\circ} / 45{ }^{\circ} \mathrm{C}$ em relação à temperatura de $45^{\circ} \mathrm{C}$ e natural. O menor valor de germinação foi observado na temperatura de $35^{\circ} \mathrm{C}$. Entretanto, isso não ocorreu em sementes submetidas à temperatura de secagem de $35^{\circ} / 45^{\circ} \mathrm{C}$ (Tabela 1 ).

Observa-se, pela Figura $5 \mathrm{~A}$, que as células da testa de sementes que foram secas à temperatura de $35^{\circ} / 45^{\circ} \mathrm{C}$ estão mais tabulares e menos espessas. O contrário foi verificado na secagem natural e aos $35^{\circ} \mathrm{C}$. Não há uma distinção de camadas nas sementes submetidas à temperatura de $45^{\circ} \mathrm{C}$. Nas sementes secas aos $35^{\circ} / 45^{\circ} \mathrm{C}$ (Figura 5B), as células da testa estão mais tabulares em relação às demais. Observa-se, ainda, uniformidade nas células da testa das sementes que foram secas aos $45^{\circ} \mathrm{C}$, mostrando que não houve danos, o que pode ser comprovado pelos testes fisiológicos. 

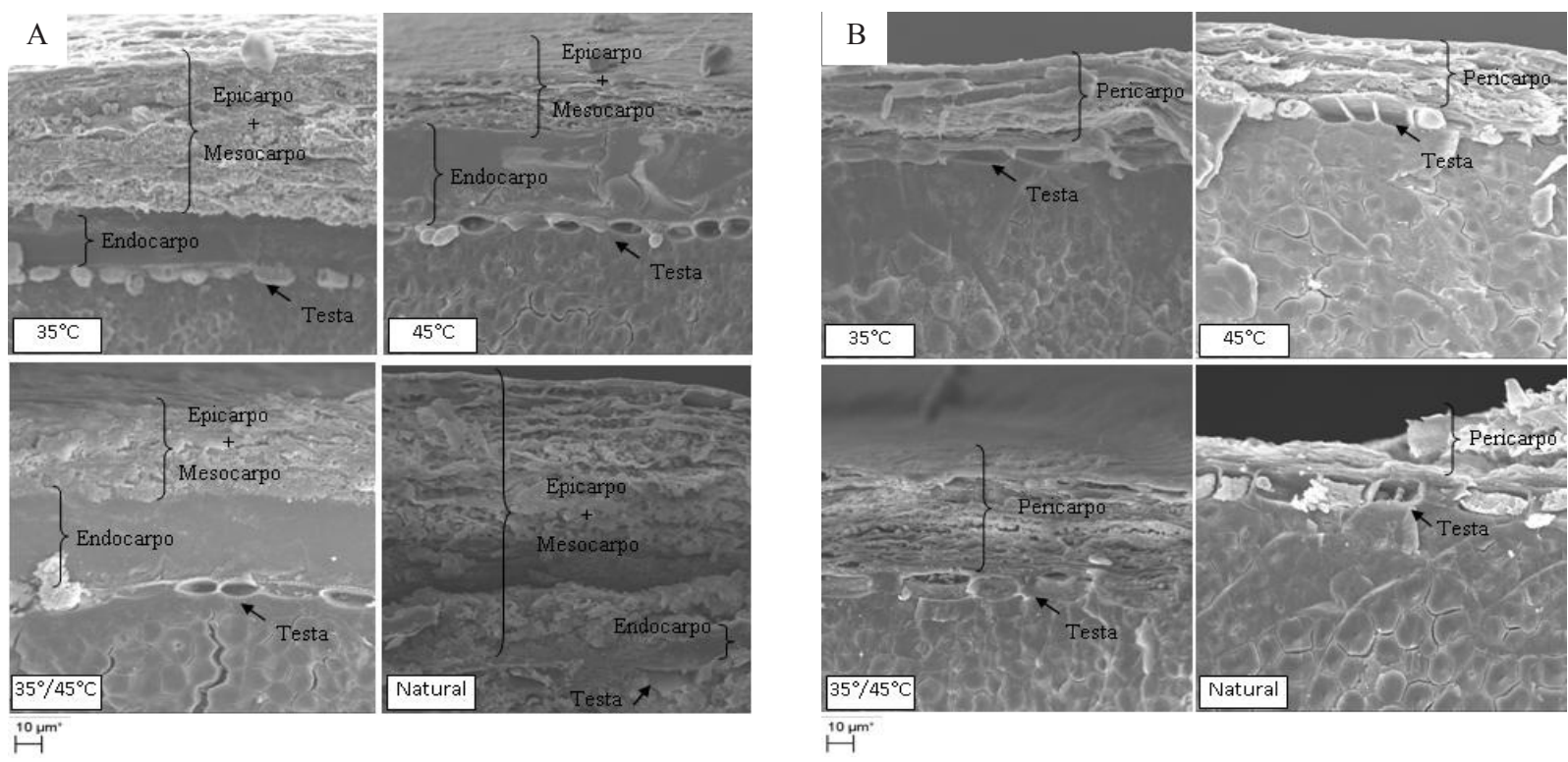

FIGURA 4. Imagens obtidas por meio de microscópio eletrônico de varredura (1000X) de sementes de sorgo cultivar BR 305 (A) e BR 310 (B) submetidas à secagem, com 3 meses de armazenamento.
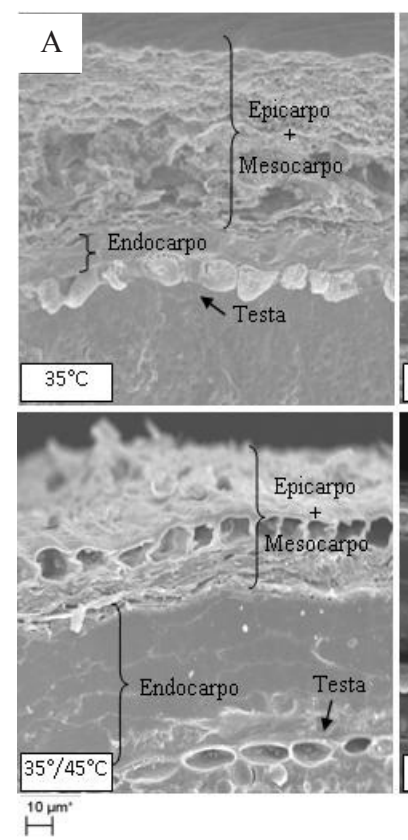
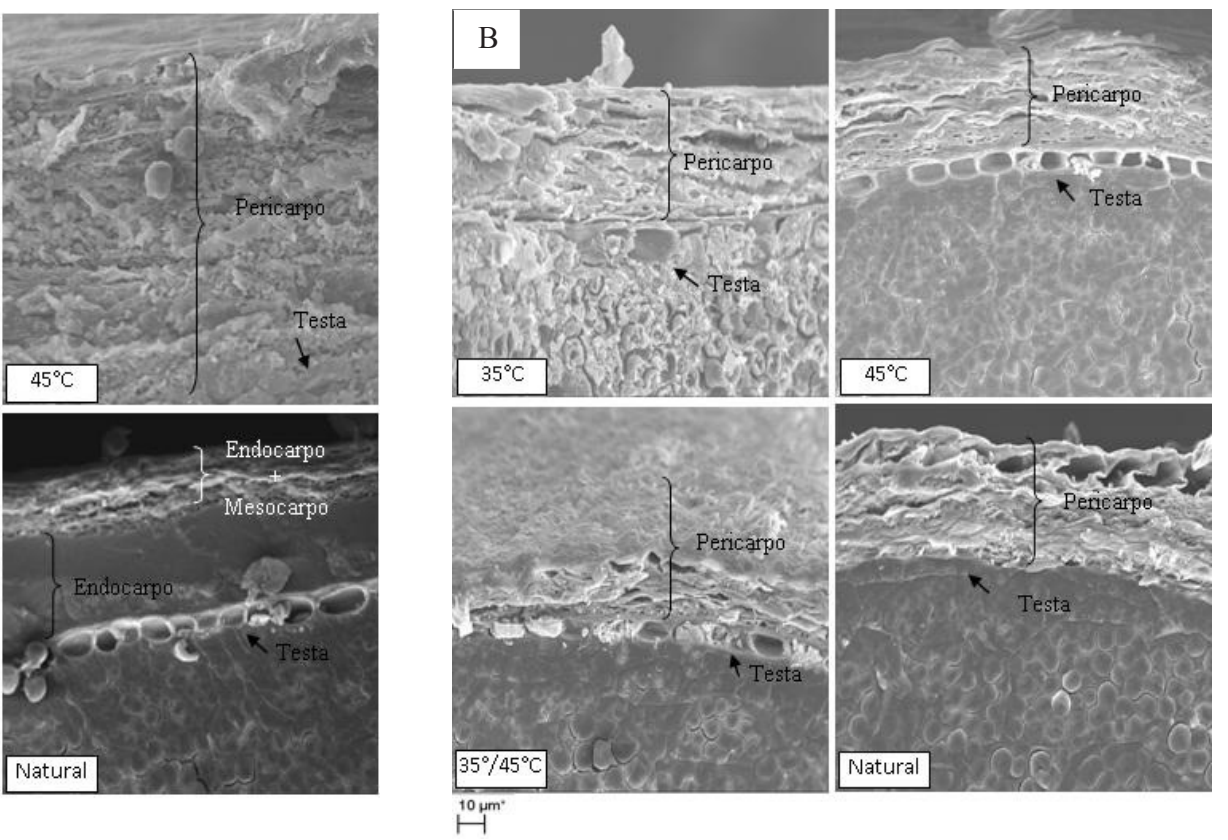

FIGURA 5. Imagens obtidas por meio de microscópio eletrônico de varredura (1000X) de sementes de sorgo cultivar BR 305 (A) e BR 310 (B) submetidas à secagem, com 6 meses de armazenamento. 


\section{CONCLUSÕES}

Durante o armazenamento em câmara fria ocorre a superação da dormência.

O teor de tanino aumenta com o armazenamento e não há uma relação direta com a dormência em sementes de sorgo.

Maior valor de germinação ocorre com sementes secas sob temperatura de $45^{\circ} \mathrm{C}$, da cultivar BR 305 .

\section{REFERÊNCIAS}

ALFENAS, A.C.; PETERS, I.; BRUNE, W.; PASSADOR, G.C. Eletroforese de proteínas e isoenzimas de fungos e essências florestais. Viçosa, MG: UFV, 1991. 242p.

ALMEIDA, F.S. A alelopatia e as plantas. Londrina: IAPAR, 1988. 60p. (Circular, 53).

AMORIM, H.V.; JOSEPHSON, R.V. Water soluble protein and non protein components of Brazilian Green coffes beans. Journal of Food Science, v.40, p.1179-1185, 1975.

ÁVILA, R.P. Sorgo em rações com diferentes níveis de proteína para poedeiras comerciais. 2007. 55f. Tese (Doutorado em Produção Animal) - Universidade Estadual do Norte Fluminense, Campos dos Goytacazes, 2007.

BRASIL. Ministério da Agricultura, Pecuária e Abastecimento. Regras para análise de sementes. Ministério da Agricultura, Pecuária e Abastecimento. Secretaria de Defesa Agropecuária. Brasília, DF: Mapa/ ACS, 2009. 395p.

BURRIS, J.S.; NAVRATIL, R.J. Drying high moisture seed corn. In: ANNUAL CORN SORGHUM RESEARCH CONGRESS., 35, 1980, Dordrecht. Proceedings... Dordrecht, 1980, p.116-132.

BUTLER, L.G. New perspetive on the antinutritional effects of tannins. In: KINSELLA, J.E.; SOUCIE, B. (Ed.). Foods products. Champaing: American oil Chemistry Society, 1989. p.402-409.

CHEN, Y.; BURRIS, J.S. Desiccation tolerance in maturing maize seed: membrane phospholipids composition and thermal properties. Crop Science, v.30, n.3, p.766-770, 1991.

DRAETTA, I.S.; LIMA, D.C. Isolamento e caracterização das polifenoloxidases do café. Coletânia do Instituto de Tecnologia de Alimentos, v.7, p.13-28, 1976.

FESSEL, S.A.; VIEIRA, R.D.; CRUZ, M.C.P.; PAULA,
R.C.; PANOBIANCO, M. Electrical conductivity testing of corn seeds as influenced by temperature and period of storage. Pesquisa Agropecuária Brasileira, v.41, n.10, p.1551-1559, 2006.

HARTMANN, H.T.; KESTER, D.E.; DAVIES JUNIOR, F.T.; GENEVE, R.L. Plant propagation: principles and practices. $6^{\text {th }}$ ed. New Jersey: Prentice Hall, 1997. 770p.

IADEROZA, M.; SALES, A.M.; BALDINI, V.L.S.; SARTORI, M.R.; FERREIRA, V.L.P. Atividade de polifenoloxidase e alterações da cor e dos teores de taninos condensados em novas cultivares de feijão (Phaseolus vulgaris L.) durante o armazenamento. Coletânia do Instituto de Tecnologia de Alimentos, v.19, n.2, p.154-164, 1989.

KRZYZANOWSKI, F.C.; VIEIRA, R.D.; FRANÇA NETO, J.B. Vigor de sementes: conceitos e testes. Londrina: ABRATES, 1999. 219p.

LIN, S.S. Alterações na lixiviação eletrolítica, germinação e vigor da semente de feijão envelhecida sob alta umidade relativa do ar e alta temperatura. Revista Brasileira de Fisiologia Vegetal, v.2, n.2, p.1-6, 1990.

LIU, M.X.; WANG, Y.W.; HAN, J.G.; MAO, P.S. The content and distribution of condensed tannins in different species of the genus sorghum (Sorghum Moench) and their effect on seed protein electrophoresis. Journal Science Food Agriculture, v.89, n.1, p.1446-1452, 2009.

MAGALHÃES, P.C.; DURÃES, F.O.M. Tanino no grão de sorgo. Sete Lagoas: Embrapa Milho e Sorgo, 2003. 2p. Embrapa Milho Sorgo. (Comunicado técnico, 88).

MAGAlHÃES, P.C.; RODRIGUES, W.A.; DURÃES, F.O.M. Tanino no grão de sorgo: bases fisiológicas e métodos de determinação. Sete Lagoas: EMBRAPACNPMS. 1997. 13p. (EMBRAPA - CNPMS. Circular técnica, 27).

MAGUIRRE, J.D. Speed of germination: aid seedling emergence and vigor. Crop Science, v.2, n.2, p.176-177, 1962.

MARCOS FILHO, J. Fisiologia de sementes de plantas cultivadas. Piracicaba: FEALQ, 2005. 495p.

MARCOS FILHO, J.; CÍCERO, S.M.; SILVA, W.R. Avaliação da qualidade de sementes. Piracicaba: FEALQ, 1987. 230p.

NUTILE, G.E.; WOODSTOCK, L.W. The influence of dormancy-inducing desiccation treatments on the respiration and germination of sorghum. Physiologia Plantarum, v.20, p.554-561, 1967. 
PAMMENTER, N.W.; BERJAK, P. A review of recalcitrant seed physiology in relation to desiccation-tolerance mechanisms. Seed Science Research, v.9, p.13-37, 1999.

PANOBIANCO, M.; VIEIRA, R.D.; PERECIN, D. Electrical conductivity as an indicator of pea seed aging of stored at different temperatures. Scientia Agricola, v.64, p.119-124, 2007.

QUEIROZ, G.M. Germinação, vigor e capacidade de armazenamento de semente de sorgo granífero, Sorghum bicolor (L.) Moench. 1979. 64f. Dissertação (Mestrado em Agronomia) - Universidade Federal do Ceará, Fortaleza, 1979.

RIBEIRO, A.C.; GUIMARÃES, P.T.G.; ALVAREZ, V.V.H. (Ed.). Recomendações para o uso de corretivos e fertilizantes em Minas Gerais. Viçosa, MG: UFV, 1999. $359 \mathrm{p}$.
SANTOS, C.M.R.; MENEZES, N.L.; VILLELA, F.A. Modificações fisiológicas e bioquímicas em sementes de feijão no armazenamento. Revista Brasileira de Sementes, v.27, n.1, p.104-114, 2005.

SILVA, J.N.; CARVALHO, J.A.; DIAS, D.C.F.; REIS, F.P. Qualidade fisiológica de sementes de sorgo coletadas em diferentes pontos de um secador. Revista Brasileira de Engenharia Agrícola, v.5, n.3, p.487-491, 2001.

TAIZ, L.; ZEIGNER, E. Fisiologia vegetal. 3.ed. Porto Alegre: Artmed, 2004.

WANISKA, R.D. Structure, phenolic compounds and antifungal proteins of sorghum caryopsis. In: CHANDRASHEKAR, A.; BANDYOPADHYAY, R.; HALL, A.J. (Ed.). Technical and institutional options for sorghum grain mold management. Patancheru: ICRISAT, 2000. p.72-106. 